\title{
¿Historiadores o Profetas del pasado?
}

\author{
José Wilson Márquez Estrada ${ }^{(*)}$
}

Recibido: abril de 2011

Aprobado: junio de 2011

\section{Resumen:}

Este artículo pretende hacer un recorrido reflexivo por la historia reciente de la disciplina histórica, resaltando la importancia del aporte de sus principales gestores y lideres científicos, a la vez, se pretende hacer un análisis de su proceso de consolidación como práctica científica. Por lo cual se hace necesario volver sobre temas tan caros a esta disciplina como son las reflexiones sobre ¿qué es la historia?, ¿cual es el oficio del historiador?, ¿qué es un hecho histórico?, ¿la historia es ciencia o arte?, ¿existen las verdades en la historia? Igualmente es importante reflexionar sobre el proceso de investigación historiográfica y sobre cual es el camino a seguir para la construcción de un sólido saber histórico. Es fundamental detenernos a pensar sobre la importancia y el papel de las fuentes para la historiografía y sobre las nuevas y viejas técnicas de investigación. Simultáneamente, intentaremos resaltar la importancia que tiene para la historiografía el diálogo interdisciplinar con otras ciencias, especialmente con las ciencias sociales.

\section{Palabras claves:}

Historia, memoria, historiografia, oficio del historiador, hecho histórico, diálogo interdisciplinar.

\section{Abstract:}

This article seeks to make a reflective journey through the history of the recent historical discipline, emphasizing the importance of the contribution of its key managers and scientific leaders, in turn, aims to analyze the consolidation process as scientific practice. Therefore it is necessary to return to themes dear to this discipline such as reflections on what is history? What is the job of the historian, what is a historical fact?, History is science or art?, are there any truths in the story? It is also important to reflect on the process of historical research and which is the way to building a strong historical knowledge. It is critical to stop thinking about the importance and role of the sources for the historiography and the new and old research techniques. Simultaneously, we will try to highlight the importance to the historiography interdisciplinary dialogue with other sciences, especially social sciences.

Key words:

History, memory, historiography, craft of the historian, historical fact, interdisciplinary dialogue.

${ }^{(*)}$ Profesor del Programa de Historia, Facultad de Ciencias Humanas, Universidad de Cartagena de Indias, Colombia. Magister en Historia, Universidad Nacional de Colombia, sede Medellín. Miembro del grupo de investigaciones Frontera, Sociedad y Cultura de dicho Programa. Ha publicado artículos en varias revistas.jmarqueze@unicartagena.edu.co 
"El historiador que solamente trabaja con archivos, directamente, sin saber nada más, está cometiendo un gravísimo error. El archivo está ahí, pero también hay que interpretarlo y para su interpretación necesita un conocimiento por parte del historiador, el tema o del contexto histórico en el cual esta trabajando".

Antonio Restrepo A. ${ }^{1}$

"La historia es la vida de la memoria".

Cicerón ${ }^{2}$

\section{Uno}

$\mathrm{H}$

ay una proposición del historiador Eduard H. Carr, que es un excelente punto de partida para intentar plantearnos la preocupación por el sentido y el valor de la historia: "pueden escribirse libros excelentes acerca del pasado, que nada tienen que ver con la historia." ${ }^{3}$ De hecho mucha gente supondría a priori que la historia es algo que tiene que ver solo con el pasado o con el estudio del pasado. Para muchos evoca en el común de los casos, un olor a naftalina, la inmovilidad y quietud temporal y la vuelta a los orígenes. Sin embargo, un principio equivoco y que hace tiempo debió haberse superado se mantiene vigente: la historia es pasado.

Precisamente Carr inicia su libro con la pregunta ¿Qué es la historia?, la cual da nombre a ese libro; entre tanto Marc Bloch, con otra que le hizo un niño: ¿para que sirve la historia? ${ }^{4}$; El primero trata de mostrar que la pregunta no es superflua, y el segundo de salvarla de una supuesta ingenuidad. No son ni lo uno ni lo otro. De hecho es claro que deberían ser las preguntas más pertinentes para quien se enfrente al oficio del historiador. Pregunta no resuelta por muchos de ellos, que como afirmábamos ahora, absorbidos por el oficio no tienen necesidad de preguntárselas y mucho menos de responderlas.

Es importante para responder traer la precisión que hace Reinhart Kosselleck ${ }^{5}$ con respecto a la historia. Distingue este autor entre la Historia empírica (Historie), las historias o los acontecimientos mismos (Geschichten), las ciencias históricas y la ciencia teórica, esto es, la histórica, que es la doctrina que estudia las condiciones de posibilidad de historias. Otros autores asocian la historia empírica con la forma de hacer la historia en el siglo XIX, es decir, la de los datos sobre los acontecimientos encadenados secuencialmente, sin pasar por una elaboración, análisis o crítica. Otra es la visión del historiador español Julio Aróstegui

1 “El oficio del historiador", en Historia y Sociedad № 10, Medellín, Universidad Nacional, 2004, pp. 35 yss.

${ }^{2}$ Marco Tulio Cicerón, De la República y Las Leyes, Turín, Ed.Einaudi, 1969.

${ }^{3}$ Eduard Carr, ¿Qué es la Historia?, Barcelona, ed. Ariel, 1999, p. 97.

${ }^{4}$ Marc Bloch, Apología para la historia o el oficio de,Historiador, México, FCE, 2001.

${ }^{5}$ Reinhart Kosselleck, Historia y Hermenéutica, Barcelona, Paidós, 1997. 
que plantea que la historia es la "entidad" o el objeto de estudio, la historiografía sería la disciplina del conocimiento de la historia, la teoría de la historia es el estudio de la naturaleza de lo histórico y teoría de la historiografía serían los conocimientos obtenidos por la disciplina historiográfica.

Para Carr la historia del siglo XIX fue la edad de la inocencia, donde se instauró el mito de los hechos y su sucedáneo: el mito del documento. La historia fue percibida como el encadenamiento de hechos objetivos, los cuales eran fundamentados en documentos que le aportaban la garantía de verdad; esto soportado en dos principios o aforismos: "los documentos hablan por si mismos" y el famoso y rankeano: "sólo mostrar lo que realmente aconteció”.Sobre esos dos pilares se escribió la historia decimonónica europea.

La historia vista como un conjunto de hechos verificables encontró en el positivismo y en el empirismo inglés dos apoyos ideológicos y dos sustentos para darle entidad científica. Desde finales del siglo XIX se empezó a cuestionar la primacía y autonomía de los hechos. Cada vez se entendió más que los datos son la materia prima de la Historia y nada más.

Otra gran preocupación surgió contra la historia de los hechos y los documentos: la carencia de una filosofía de la historia. Desde finales del siglo XIX, desde Wilhelm Dilthey $^{6}$ a Benedetto Croce ${ }^{7}$, de Alemania a Italia, se abogó por una filosofía de la historia que le definiera un derrotero y un pensamiento al oficio. Croce planteó que el problema no era recoger datos sino valorarlos. Los hechos nunca nos llegan en estado puro y sólo conoceremos el pasado a través del cristal del presente. ${ }^{8}$ Sin duda que la pretensión no es mantenerse atado al pasado. Hay que tener en cuenta que el historiador vive en presente y trabaja con los hechos del pasado, los cuales de alguna manera también actúan en el presente. De ahí que la función del historiador es dominar y comprender el pasado para poder entender el presente. Definitivamente la historia se mueve entre dos polos, los hechos y su interpretación, es decir, entre lo objetivo y lo subjetivo; donde uno no es humilde siervo y el otro tiránico dueño de los datos. De aquí se desprende la respuesta de Carr a la pregunta ¿qué es la historia?: "un proceso continuo de interacción entre el historiador y sus hechos, un diálogo sin fin entre el presente y el pasado."

Lo que si es evidente es que del apego a precisar los hechos a partir de los documentos, a buscar su verdad, es decir, el positivismo, surgió el distanciamiento objetivista de la historia. Una impersonalidad que le quitó parte del arte narrativo, de la "forma" a la escritura. Considerada mas arte que ciencia, en un principio, pasó a ser ciencia que intentó

\footnotetext{
${ }^{6}$ Filósofo alemán (1833-1911) que negando la posibilidad de la metafísica como sistema definitivo y absoluto, colocaba al hombre y su filosofía en la corriente histórica, planteando que el problema central de la historia era la comprensión de la vida.

${ }^{7}$ Filósofo italiano (1866-1952). Su pensamiento, del que es punto central la identificación de la filosofía con la historia, ejerció una profunda influencia en la cultura italiana de la primera mitad del siglo XX. Sus obras principales son "Estética como ciencia de la expresión" y "Filosofía del Espíritu".

${ }^{8}$ E. Carr, ¿Qué es la Historia?, p. 70.

${ }^{9}$ E. Carr, ¿Qué es la Historia?, p. 76.
} 
lo medible o cuantificable. En ese tránsito perdió parte de riqueza formal en pos de la precisión del dato, la cuantificación o las series. Pasando por alto que todo en lo humano no es matematizable, por eso donde "es imposible calcular, se impone sugerir", teniendo que tener en cuenta que "cada ciencia tiene su propia estética del lenguaje". De ahí que para una ciencia de lo humano como es la historia deba recurrir a un adecuado tratamiento de la palabra, una estética que no le quite ni precisión ni posibilidad de lindar con otras ciencias.

Para Marc Bloch, la acción del pasado sobre el presente no necesariamente se da en un sentido lineal y consecutivo. Hay retrocesos generacionales, influencias distantes en el tiempo que se recogen en el presente y otras múltiples maneras que no tiene que ver con una acción inmediata en el tiempo o en el espacio. Por mas inmutables que parezcan, las cosas cambian; aún el hombre. Pero por más que cambien las cosas siempre habrá en la naturaleza humana y en las sociedades humanas un fondo permanente, sin el cual los nombres mismos de hombre y sociedad no significarían nada. ${ }^{10}$ Según Bloch, el historiador debe tomar de su propia experiencia elementos y argumentos para insuflarle vida a los documentos y al pasado. Pero, ¿para qué sirve la historia?, no solo para extraer lecciones morales, recordemos como la historia, entendida como estudio del pasado justificó procesos nacionalistas, creó naciones o en términos de Benedick Anderson, "sociedades imaginadas", llegando a puntos como considerar que estudiar su secuencia en términos del pasado podía aventurar el porvenir. Se lanzó así a establecer las leyes históricas y convertirse en una ciencia predictiva. El darle un propósito iba aparejado con el sentido de la historia, es decir, con un avance infinito hacia el progreso material y la felicidad espiritual. Con la caída del sentido también se empezó a dudar del valor, importancia y aporte de la historia. Por ejemplo para historiadores como Paul Veyne, ${ }^{11}$ la historia es una actividad intelectual y por tanto un hecho cultural, ante lo cual entra como una dimensión antropológica, pero sin efectos sobre la historicidad, esto es, la acción. Se caracteriza por ser "uno de los productos más inofensivos que haya elaborado nunca la química mental; desapasiona y hace perder valor a los objetos", esto es, una especie de criba mental que le hace perder efecto, por eso su verdad es siempre decepcionante. Para este autor a lo sumo el interés por ella tiene dos causas: el sentido de pertenencia que da a un grupo familiar, social o nacional y la curiosidad por el pasado y por el entendimiento de ese pasado.

En el otro extremo de Veyne esta Carr, que lejos de este pesimismo y escepticismo, es un convencido de la razón y los logros obtenidos por la historia. Para este maestro solo era posible la historia en tanto la lucha del hombre, mediante la razón, para comprender el mundo que lo rodeaba y actuar sobre él. Si la historia no "sirve" en términos pragmáticos al menos distrae en el sentir de Marc Bloch. En ella hay diversión, voluptuosidad, goce y poesía.

\footnotetext{
${ }^{10}$ M. Bloch, Apología para la historia o el oficio de,Historiador, p. 70.

${ }^{11}$ Paul Veyne, Como se escribe la historia. Ensayo de epistemología, Madrid, ed. Fragua, 1972, p. 37.
} 


\section{Dos}

El positivismo del siglo XIX, originado en el pensamiento del sociólogo Augusto Comte, pretendió darle a la historia el estatuto de ciencia con la estricta observancia de los hechos, el apegamiento a los documentos y el encadenamiento cronológico de los hechos aportado por los documentos; esto era en sí mismo la evidencia, la objetividad y la verdad, por lo tanto en esto consistía su carácter científico.

De acuerdo con Carr, tres principios rigieron la manera de hacer la historia desde finales del siglo XVIII hasta, al menos, principios del siglo XX: la cronología, la causa-efecto y las leyes históricas. El positivismo, en palabras de Hobsbawn, introdujo "conceptos, métodos y modelos de las ciencias naturales en la investigación social y aplicar a la historia los descubrimientos de las ciencias naturales que parecieran apropiados". ${ }^{12}$ Las taxonomías de Linneo ${ }^{13}$, por un lado y el evolucionismo de Darwin, por el otro, marcaron rumbos: la primera definió la manía clasificatoria y el segundo fue acogido generosamente para plantear formas sociales evolutivas, es decir, un determinismo que permitía aventurar leyes históricas abstractas y universales.

La relación entre ciencia e historia para Carr, toca al menos cinco puntos esenciales:

- La historia se ocupa de lo particular y la ciencia de lo general.

- La historia no enseña nada.

- La historia no puede pronosticar.

- La historia es forzosamente subjetiva por que el hombre se esta observando así mismo.

- La historia a diferencia de la ciencia, implica problemas de religión y de moralidad.

Por el contrario, la ciencia para Marc Bloch era indudablemente una ciencia por su objeto y sus métodos. Toda ciencia era para él la que lograba establecer entre los fenómenos nexos explicativos, para lo cual la historia lo que tenía que hacer como ciencia en lugar de una mera enumeración era "una clasificación racional e inteligibilidad progresiva". Era válida como tal si está penetrada por lo racional y lo inteligible. Pero era una historia no de lo natural sino de lo humano, entendida obviamente como una ciencia en movimiento. Pero era una ciencia que no podía caer solo en abstracciones, leyes y estructuras, eliminándole su parte poética, su propio goce estético que estaba en la forma de narrar. Los enfoques de Carr y Bloch se acercan en este sentido, frente a la necesidad de explicaciones racionales; de tener marcos explicativos que no son leyes. Pero mientras para Carr el azar no cumple

12 Eric Hobsbawm, Sobre la Historia, Barcelona, Ed. Crítica, 1998, capitulo ¿Qué deben los Historiadores a Karl Marx?, p. 150.

${ }^{13}$ Karl von Linné (1707-1778).Naturalista y médico sueco más conocido como Linneo. En "Systema Naturae", su máxima obra, estableció las bases de la taxonomía natural botánica en función de los órganos sexuales de las plantas, y desarrolló la nomenclatura binaria, todavía vigente. 
un papel en la historia, para Bloch es el azar la que hace imposible el cumplimiento de las leyes. En cambio para Hobsbawm, el error del positivismo es tratar de explicar lo humano a partir de lo no humano.

La sociología, las matemáticas, la antropología, la hermenéutica son algunas de las ciencias que tienen relación con la historia. Con algunas de ellas hay una correlación, con otras una pretensión de subordinación, por ejemplo, Gadamer ${ }^{14}$ asume que la historia es un subcaso de la hermenéutica. ${ }^{15}$ Para otros autores la historia es una rama de la sociología, lo cual exasperaba al maestro Bloch; pero lo que sí es evidente es que la historia es la disciplina que más puentes ha tendido con las demás ciencias sociales. Lo que no podemos negar es que la historia le debe mucho a la sociología, especialmente al sociólogo francés Emile Durkheim. La sociología le aportó el método comparativo, la posibilidad de generalizar, que no tenía en sus inicios. Sólo un historiador profundamente renovador como Marc Bloch, fue capaz de sacar con beneficio crítico, todas las conclusiones que para una historia cultural ofrecía la obra de Durkheim, sobre todo darnos a entender el carácter histórico de todo fenómeno social. En este sentido, el análisis sociológico e histórico, están presentes desde el marco cronológico amplio hasta el entendimiento de los procesos de larga duración y las inercias sociales, aquello que después se llamaría historia de las mentalidades y de los imaginarios, donde también entra a participar la antropología.

La antropología es otra de las disciplinas que le ha aportado fuertemente a la historia, en cuanto le ha servido para localizar nuevos problemas, ver los viejos desde una nueva mirada, poder enfatizar sobre las normas, los sistemas de valores o los rituales, atender a las funciones expresivas de las formas de tumulto y disturbio, y lo que significan como expresiones simbólicas la autoridad, el control y la hegemonía. ${ }^{16}$

La historia es la forma científica de la memoria colectiva y como tal hace uso del monumento y del documento, como materiales propios de la memoria. ${ }^{17}$ Monumento y documento durante muchos siglos se confundieron, ambos eran textos supervivientes del pasado. A partir del siglo XIX comenzaron a ser diferenciados, pues mientras el monumento se asoció a condiciones físicas, de índole celebratorio, con una intencionalidad de quienes lo construyeron, como forma de proyección de la memoria colectiva. El documento se consideró fundamentalmente como un texto escrito, que desde Jean Mabillón ${ }^{18}$ - en cierto sentido creador del documento escrito y su uso crítico-, cobró importancia para la historia y se posicionó como fundamento de ésta a partir de la escuela

${ }^{14}$ Recomiendo al respecto el texto del filósofo Hans Georg Gadamer, La dialéctica de Hegel: cinco estudios hermenéuticos, donde aparece con mayor claridad su visión de la historia

${ }^{15}$ R. Kosselleck, Historia y Hermenéutica, p. 69.

${ }^{16}$ E. P. Thompson, Agenda para una historia radical, Barcelona, ed. Crítica, 2000, p. 16.

${ }^{17}$ Jacques Le Goff, El orden de la Memoria. El Tiempo como imaginario, Barcelona, Ed. Paidós, 1991, pp. 227-239.

${ }^{18}$ Benecditino francés, nació en 1632 y murió en 1707, se le considera el fundador de la Diplomática con su obra De re diplomatica libri VI. Maestro pionero de la crítica documental y del estudio de la autenticidad de los documentos, esencial para los estudios históricos. 
positivista del siglo XIX; entendido como la prueba histórica escrita. Desde entonces no se concibe una historiografía que no este basada en él, por lo que se convirtió en si mismo prueba de verdad histórica absoluta y con alto grado de objetividad, llegando a los limites de fetichización.

El documento utilizado en extenso por la escuela positivista era por excelencia texto, pero desde entonces comenzó a ampliar su acepción, especialmente desde La Escuela de Annales, cuando comenzó a asociarse, a todos aquellos registros más allá de lo escrito, que el hombre hubiera elaborado, que dieran cuenta de su existencia y que sirviera para estudiar los hombres y las sociedades que los elaboraron; así se extiende el documento a lo pintado, lo esculpido, lo sonoro o la imagen, entre otros. A partir de los años sesenta se plantea una verdadera Revolución Documental, tanto en lo cualitativo como en lo cuantitativo. A la expansión de la memoria documental se le sumó la posibilidad de su procesamiento por medio de la informática, con lo que se dio surgimiento a la historia cuantitativa "que pone en discusión la noción de documento y el modo de usarlo"19 y desarrolla el valor del mismo. La concepción de objetividad en si mismo se pone en entredicho, ahora comporta un valor relativo y se convierte en objetivo únicamente en relación con otra serie de documentos, esto es, se convierte en un dato. Esta revolución no se queda en el número o en la serie, sino que implica un cambio profundo en el "conciencia historiográfica".

Si la separación de un objeto lo convertía en documento, y si este, sometido a una serie se volvió dato, en los últimos decenios opera un cambio en la calidad de documento hacia el dato. Esta operación inversa a lo que ocurrió antes con la relación documento/ monumento, parte en la crítica profunda. En un principio la crítica, por la filología o la diplomática, tendía al establecimiento de la autenticidad del documento; después de pretender que el documento hablaba por si mismo está "debía hacer hablar al documento" y ahora se plantea que "solo el análisis del documento en cuanto documento permite a la memoria colectiva recuperarlo y al historiador usarlo científicamente, es decir con pleno conocimiento de causa" ${ }^{\text {"20 }}$. Este es el paso que se pretende para una entidad de ciencia histórica. Tal como señala Michel Foucault, "la historia es la que transforma los documenti en monumenti, y que allí, donde se descifraban los vestigios dejados por los hombres y se descubría en negativo lo que habían sido, presenta un conjunto de elementos que es preciso luego aislar, reagrupar, volver pertinentes, poner en relación, construir en conjunto". ${ }^{21}$

\footnotetext{
${ }^{19}$ J. Le Goff, El orden de la Memoria, p. 232.

${ }^{20}$ J. Le Goff, El orden de la Memoria, p. 237.

${ }^{21}$ J. Le Goff, El orden de la Memoria, p. 237. Para acercarnos al debate sobre la importancia de Michel Foucault para el pensamiento histórico recomiendo la siguiente bibliografía: Jacques Leonard, El Historiador y el Filósofo, en la imposible prisión, debate con Michel Foucault, Barcelonan, Anagrama, 1982. Paul Veyne, "El Planeta Foucault", en Otras Quijotadas, № 2. Medellín, 1985. Silvie Le Bon, "Un positivista desesperado: Michel Foucault", en Análisis de Michel Foucault, Madrid, Tiempo Contemporáneo, 1970, p’. 94 y siguientes. Michel Foucault ha sido reseñalado por historiadores como Paul Veyne como un verdadero revolucionario de la historia, en este sentido, recomiendo, quizá la obra foucaultiana más importante para la formación de todo historiador, La Arqueología del Saber donde expone su revolucionario concepto de Archivo.
} 


\section{Tres}

En el siglo XVIII la historiografía parece traducir de forma evidente la intensa ideología del iluminismo, la confianza de los filosophes en la renovación de una determinada época, basada fundamentalmente en el racionalismo. En este sentido, los historiadores de este siglo terminan viendo el pasado como el lugar común de la superstición, la metafísica, los prejuicios y la violencia. Voltaire ${ }^{22}$, quien decía que "el pasado, la edad medieval, esta llena de los engaños de los curas, de las intrigas de los cortesanos y de la ignorancia de la plebe". Lo anterior no quiere decir que el siglo XVIII sea un siglo anti-histórico, por el contrario, encontramos allí una intensa aplicación del campo de investigación de la historia, una historia que tiende a convertirse en historia universal, atenta a todos los aspectos de la actividad del hombre, precursora de las futuras ciencias sociales, sensible a los procesos de transformación económica, de desarrollo social y de circulación de culturas. Autores como Edward Gibbon con su obra Historia de la grandeza y de la decadencia de Imperio Romano (1788), David Hume con La Historia de Inglaterra (1761), Voltaire con El Siglo de Luis XIV (1751) y Adam Ferguson con su obra Ensayos sobre la Historia de la Sociedad Civil (1766); nos entregan un rico y móvil cuadro de las sociedades humanas.

El siglo XIX es el siglo de la historia, marcado por el nacionalismo, que es la palabra clave para entender las luchas políticas europeas en ese periodo, enriquecidas por la simbología de los nuevos estados nacionales. Los trabajos de los historiadores del siglo XIX reflejan todo este ambiente de luchas independentistas, de ideologías nacionales, de construcción de estados nacionales y es a ellos a quienes se les confía la tarea ideológicamente crucial de reconstruir los orígenes de las nuevas naciones. Los historiadores se convierten en los constructores de las historiografías nacionales y a la vez en personajes de prime plano en el campo político de sus países. Es el siglo en que la historia alcanza el estatus de disciplina profesional y se enseña en todas las universidades, primero en Alemania y luego en toda Europa. Es el siglo de los millares de publicaciones de temas de historia, de los lugares dedicados a la conservación de fuentes documentales o archivos, de las sociedades de historiadores, de las revistas de historia, de los manuales de metodología histórica y de los grandes eventos de encuentros de historiadores. Este siglo XIX caracterizado por un paradigma historiográfico donde se exalta la idea de nación, de estado, de libertad, de pueblo; donde se privilegia el análisis político-diplomático, donde se avanza en el uso crítico de las fuentes documentales, donde se asume a menudo connotaciones finalistas conectados a la idea de progreso, empieza a colapsar a principios del siglo XX, cuando los franceses de Annales plantean toda una revolución para la historia, imponiendo todo un novedoso paradigma historiográfico que va a marcar el derrotero de toda la historiografía de occidente, ampliando el objeto y convirtiendo en fuente histórica todos los innumerables

${ }^{22}$ Seudónimo de Francois-Marie Arouet (1694-1778). Su obra histórica más importante fue El Siglo de Luis XIV, otro de sus más bellos textos fue Ensayo Sobre las Costumbres. Es considerado el más ilustrado de los enciclopedistas, racionalista a ultranza, criticó toda forma de fanatismo y de intolerancia religiosa. 
indicios directo o indirectos de la presencia humana; pero sobre todo conectando a la historia con las demás ciencias sociales.

\section{Conclusión}

Hoy, gracias a la trayectoria y a los aportes de los historiadores en el devenir complejo de esta disciplina por todos los tiempos, podemos decir que los historiadores del siglo XXI, a pesar de las crisis normales que vive y atraviesa nuestra disciplina en su constante renovación y en su constante proceso de construcción, estamos dispuestos a asumir los retos que en el campo historiográfico este conflictivo siglo nos depara, afirmándonos como lo que somos historiadores o pensadores que, fundamentados en una práctica científica, producimos sentido y conocimiento sobre el pasado o como lo dice Hans Konig, construimos profecías sobre el pasado. 